\title{
Allen Lowrie's DEFINITIVE WORK ON Australian CARNiVOROUS Plants - Carnivorous Plants of Australia Magnum Opus
}

\author{
RICHARD NUNN • NSW •Australia・richardjnunn1@gmail.com
}

In her 1968 volume 'Plants of Prey', Rica Erickson made the first attempt to consolidate the complete known roster of Australia's carnivorous plants into one single work. For two decades this was the standard on the topic, however during that time many new species were discovered and taxonomic issues solved. Allen Lowrie's original 3 volume work, 'Carnivorous Plants of Australia', released in 1987, 1989, and 1998, was at the time an enormous achievement and was the benchmark reference that made it possible for naturalists, carnivorous plant enthusiasts and botanists to identify specimens in the field. For the first time colour images of every species were included and many new species described since Erickson's work were added. Even as his original 3 volume work was completed, it was out of date, something acknowledged in Volume 3. The obvious gap was the Utricularia of northern Australia, but Lowrie was a great believer in getting the work out there and then over time adding to it as new information and discoveries became available. In discussions with Allen in the early 2000s it became obvious that his first books were merely a placeholder for what was to be a more complete treatment of Australia's carnivorous plants and the culmination of his life's work.

In 2014, after 35 years of research and publishing, 'Carnivorous Plants of Australia Magnum Opus' was released. Over 3 volumes, 1371 pages and 2573 images, Allen treated all known Australian taxa at the time. There were new combinations, new records, new taxonomic states, synonyms re-elevated to species level, new sections, and the description of several new species: 1 Byblis, 16 Drosera, 1 Utricularia, as well as new Drosera hybrids. Each species entry had a first page containing a full botanical description, distribution, habitat, flowering period, etymology, affinities, and notes. The second page displayed Allen's botanical line drawings, highlighting important characters for each species. The third page showed a satellite distribution map, as well as a key to the multiple images on the fourth page. In addition to the species covered, there was a wealth of other information including, habitat and ecology, historical accounts, comprehensive keys, sections on flowers and gemmae, and a biography of all the authors of Australian carnivorous plant species. Quite simply this was the definitive work on Australia's carnivorous plants and a testament to the life work of Allen Lowrie.

Even as Magnum Opus was released it was already out of date, such is the amount of unexplored habitat on the vast Australian continent. Allen's intention was to release a fourth volume to cover the new discoveries that he and others were working on, however as his health declined this project was never completed.

To commemorate the legacy of Magnum Opus and Allen Lowrie, this edition of Carnivorous Plant Newsletter has compiled over the following 3 papers a complete list of new Australian carnivorous plants published since 2014. The authors are acutely aware that as we go to print, this treatment is already out of date but hope that it adds to the store of knowledge left to us by Allen Lowrie.

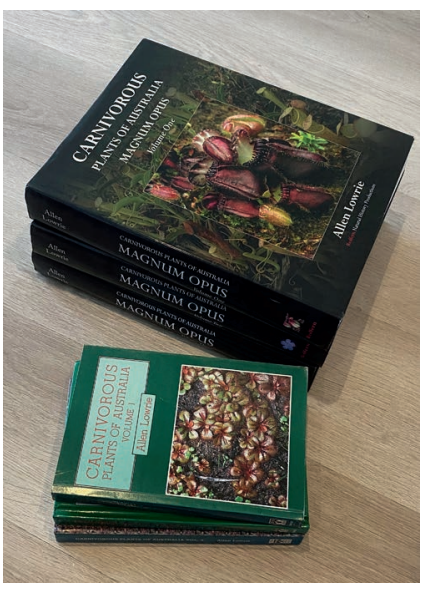

Lowrie's Magnum Opus in comparison to his original Carnivorous Plants of Australia. 